OPEN ACCESS

Edited by:

Andy Pereira

University of Arkansas, United States

Reviewed by:

Mirza Hasanuzzaman,

Sher-e-Bangla Agricultural University,

Bangladesh

Madana M. R. Ambavaram,

Metabolix, United States

Omar Borsani.

Universidad de la República, Uruguay

*Correspondence:

Huiying $L$

lihuiying@wbgcas.cn

Jinmin Fu

jfu@wbgcas.cn

Specialty section: This article was submitted to

Plant Abiotic Stress,

a section of the journal

Frontiers in Plant Science

Received: 26 June 2017 Accepted: 06 August 2018 Published: 22 August 2018

Citation:

Hu L, Bi A, Hu Z, Amombo E, LiH and Fu J (2018) Antioxidant Metabolism, Photosystem II, and Fatty Acid Composition of Two Tall Fescue Genotypes With Different Heat

Tolerance Under High Temperature Stress. Front. Plant Sci. 9:1242. doi: 10.3389/fpls.2018.01242

\section{Antioxidant Metabolism, Photosystem II, and Fatty Acid Composition of Two Tall Fescue Genotypes With Different Heat Tolerance Under High Temperature Stress}

\author{
Lianlian $\mathrm{Hu}^{1,2}$, Aoyue $\mathrm{Bi}^{1,2}$, Zhengrong $\mathrm{Hu}^{1,2}$, Erick Amombo ${ }^{1,2}$, Huiying $\mathrm{Li}^{{ }^{*}}$ and \\ Jinmin Fu',3*
}

\begin{abstract}
${ }^{1}$ Key Laboratory of Plant Germplasm Enhancement and Specialty Agriculture, Wuhan Botanical Garden, The Chinese Academy of Sciences, Wuhan, China, ${ }^{2}$ University of Chinese Academy of Sciences, Beijing, China, ${ }^{3}$ The Institute for Advanced Study in Coastal Ecology, Ludong University, Yantai, China
\end{abstract}

Tall fescue (Festuca arundinacea Schreb.) is a typical and widely used cool-season turf grass. High temperature is a key factor that limits its utility. The objectives of this study were to investigate the behaviors of fatty acid composition and its gene expression patterns in heat-resistant genotype "TF71" and heat-sensitive genotype "TF133" exposed to heat stress $\left(40 / 35^{\circ} \mathrm{C}, 14 / 10 \mathrm{~h}\right)$, and to broaden our comprehension about the relationship between heat tolerance and fatty acid function. The result showed that heat stress increased the malondialdehyde (MDA) content and relative electrolyte leakage (EL), but decreased the level of chlorophyll and the activity of superoxide dismutase (SOD) and peroxidase (POD) when compared to the controls, to a greater extent in "TF133." This result proved that "TF71" had superior hightemperature resistance. Furthermore, comparing the changes in the composition of fatty acid and the expression of the genes involved in its synthesis between the two different genotypes under heat stress, we found that heat stress increased the degree of unsaturation, UFA/SFA, and double bond index (DBI) in "TF71." Moreover, quantitative RT-PCR revealed that heat stress altered the expression of the genes involved in fatty acid synthesis, including ACAC, FabD, FabF, FabH, Fabl, and FatA. According to these findings, we can speculate that increasing the unsaturation degree of fatty acid or controlling the equilibrium ratio of UFA/SFA might be closely associated with the improving of the heat resistance in tall fescue.

Keywords: tall fescue, heat stress, antioxidant metabolism, photosystem II, fatty acid composition, gene expression

\section{INTRODUCTION}

Supra-optimal temperature is an important factor that limits the widespread use of cool-season turf grass in transitional and warm climatic regions, causes decline in turf quality, and leads to growth retardation and irreversible damage (Kotak et al., 2007). In addition, heat stress can induce a series of changes including enzyme activity, membrane fluidity, metabolism homeostasis, and genes transcription (Knight and Knight, 2001). 
Plant cell membranes are one of the most sensitive parts during the perception of heat stress. The adaptability of cell membranes under high-temperature stress reflects the ability to adapt to adverse environmental conditions (Georgieva, 1999). Malondialdehyde (MDA) content and relative electrolyte leakage (EL) are effective indicators of the thermal stability of the cell membrane, and also considered as two effective indices to reflect the direct damage degree of heat stress on the plants. Many experiments have confirmed that high-temperature stress can cause the accumulation of reactive oxygen species (ROS) in plants, thereby causing membrane lipid oxidation, which is regarded as an oxidative stress (Liu and Huang, 2000; Huang et al., 2001). For self-protection against oxidative stress, plants up-regulate the activities of antioxidant enzymes such as superoxide dismutase (SOD) and peroxidase (POD) to scavenge ROS (Cushman and Bohnert, 2000).

Negative effects of heat stress on plants are largely due to their impact on photosynthesis. One of the most thermosensitive sites in the photosynthetic is considered to be photosystem II (PS II) and its activity decrease significantly under heat stress (Zhao et al., 2008). Many studies have shown that high temperature stress has three main effects on PS II function. First, high temperature induces a dissociation of the peripheral antenna complex of PSII from its core complex. In addition, high temperature leads to the deactivation and dissociation of the oxygen-evolving PS II complexes (Busheva et al., 2012). Furthermore, high temperature stress inhibits the electron transfer from the primary acceptor plastoquinone $\left(\mathrm{Q}_{\mathrm{A}}\right)$ to the secondary acceptor plastoquinone $\left(\mathrm{Q}_{\mathrm{B}}\right.$; Pospísil and Tyystjärvi, 1999; Liu et al., 2002). The oxygen-evolving PS II complexes contain the intrinsic chlorophyll-binding proteins (CP43 and CP47; Pagliano et al., 2011). Overcoming photo damage to PS II is a rapid and efficient method for damage repair in photosynthetic organisms, which requires the de novo synthesis of the abovementioned proteins (Yang et al., 2015).

Under heat stress, plants exhibit various mechanisms for surviving. They can tolerate high temperature by modifying the antioxidant system. For example, heat-resistant cool-season turf grass species had lower production of ROS compared to heatsensitive species (Xu et al., 2006). Besides, photorespiration is a mechanism by which plants protect the photosynthetic apparatus against high temperature (Veste et al., 2000). Furthermore, in case of sudden heat stress, the changes in membrane lipid composition are very important for survival (Zabed and Shuichi, 2013), but its specific mechanism is not clear in turf grass under heat stress.

Previous studies have shown that the composition and saturation of lipids are closely associated with the plant ability to adapt to stress (Sui et al., 2010; Sanghera and Sharma, 2011). The total fatty acid content of plant was comprised of polyunsaturated fatty acids (PUFAs) mainly including linoleic acid (C18: 2) and linolenic acid (C18: 3), monounsaturated fatty acids (MUFAs) mainly including oleic acid (C18: 1$)$, and the remaining is saturated fatty acids (SFAs) mainly including palmitic acid (C16: 0) and stearic acid (C18: 0; Mishra et al., 2015; Janila et al., 2016). Palmitic acid, stearic acid, linoleic, and linolenic acid are the four major fatty acids, as well as the major components of membrane lipids. Many experiments have confirmed that the unsaturation degree of fatty acids in cell membranes increased under supra-optimal temperature. The high level of fatty acids, especially unsaturated fatty acids (UFAs), can preferably maintain the fluidity of plant cell membrane lipids under stress (Peng et al., 2013), since the UFAs have double bonds, and more common double bonds to help to keep membrane fluidity (Vigh et al., 1998).

A series of enzymes including acetyl-CoA carboxylase, fatty acid synthase (FAS), fatty acid desaturase, and fatty acid elongase are involved in complex fatty acid biosynthesis pathways. The biosynthesis of long-chain fatty acids occurs in two different steps, i.e., the conversion of acetyl-CoA to malonyl-eoA, which is catalyzed by acetyl-CoA carboxylase. Subsequently, acetyl-eoA and malonyl-CoA are converted to palmitate in the presence of NADPH, which is catalyzed by the FAS (Wakil et al., 1983). FAS system is a prokaryotic multi-enzyme complex (type II FAS), which consists of an acyl carrier protein, an acyl acyltransferase, a malonyltransferase, a $\beta$-ketoacyl-ACP synthetase, a $\beta$-ketoacyl-ACP reductase, $\beta$-Hydroxyacyl-ACP dehydratase, and $\beta$-enoyl-ACP reductase ( $\mathrm{Lu}, 2000)$. The process of linolenic acid biosynthesis is complicated and catalyzed by a battery of desaturase enzymes. First, stearoyl-ACP desaturase converts stearic acid to oleic acid (C18:1). Then C18: 1 is catalyzed by oleoyl-PC desaturase to form a linoleic acid (C18: 2). Finally, the formation of linolenic acid (C18: 3 ) is executed by linoleoylPC desaturase (Cyril et al., 2002).

Tall fescue (Festuca arundinacea Schreb.), a typical coolseason forage and turf grass species which grows in the temperate regions of the world. This turf grass has been widely cultivated for its major vegetative ground cover in landscape on account of its fast reproduction and strong resistance to drought, wear, and disease (Bush and Fannin, 2009). However, with global warming, the supra-optimal temperature becomes a key factor that limits tall fescues' growth and utility. Our previous studies indicated that there was a great variation in heat tolerance among different tall fescue genotypes (Sun et al., 2014). However, up to date, there is limited information about the responsive differences among different genotypes under high temperature.

In this study, a heat-sensitive tall fescue genotype "TF133" and a heat-resistant genotype "TF71" were selected to investigate the different responses to high-temperature stress, and the possible mechanism involved in heat resistance in tall fescue. The membrane peroxidation, PS II photochemistry combined with fatty acid composition and gene expression patterns in response to heat stress were investigated between the two distinct tall fescue genotypes. This is the first study to demonstrate the heat resistance differences from the aspect of fatty acids. The study will provide useful insight into the relationship between the fatty acids function and heat tolerance.

\section{MATERIALS AND METHODS}

\section{Plant Materials}

The study was conducted at Wuhan Botanical Garden, Chinese Academy of Sciences, Wuhan, China, in 2016. Two tall fescue genotypes heat-sensitive "TF133" and heat-tolerant "TF71" were 
used in this study. The seeds were sowed in plastic pots $(13 \mathrm{~cm}$ in diameter and $15 \mathrm{~cm}$ in depth) filled with nutrient soil, and there were 20 pots of material (10 for each genotype). The pots were then kept in a greenhouse with a daily maximum/minimum temperature of $22 / 18^{\circ} \mathrm{C}$ at $14 / 10 \mathrm{~h}$ photoperiod for 40 days to establish the tall fescue plant. The plants were then watered daily and fertilized twice a week with a half-strength Hoagland nutrient solution (Hoagland and Arnon, 1937), and mowed at $6 \mathrm{~cm}$ above the sand surface.

Before the treatments, 20 pots of the plants were transferred into the incubators for pre-adaptation. The plants were grown under controlled conditions for 7 days [light/dark regime of $14 / 10 \mathrm{~h}$ at $22 / 18^{\circ} \mathrm{C}$, relative humidity of $70 \%$, photosynthetic photon flux density of (PAR) $360 \mu \mathrm{mol} \mathrm{m}^{-2} \mathrm{~s}^{-1}$ ] and were subirrigated every other day with full-strength Hoagland nutrient solution.

\section{Heat Treatments}

After 7 days of pre-adaptation, each genotype of tall fescue was divided into two identical groups (five pots for one group) and transferred into two growth incubators with the same growth condition except for temperature, respectively. The temperature of one incubator was set at $22 / 18^{\circ} \mathrm{C}$ (day/night) (optimal temperature), while the other was set at $40 / 35^{\circ} \mathrm{C}$ (high temperature), respectively. High temperature $\left(40 / 35^{\circ} \mathrm{C}\right)$ was selected according to the previous study (Zhao et al., 2015). Therefore, the plants were subjected into four treatment regimes and each had five pots: (i) "TF133" under optimum temperature (SCK); (ii) "TF71" under optimum temperature (TCK); (iii) "TF133" under high temperature (SH); and (iv) "TF71" under high temperature (TH). The heat treatment began immediately and the temperature rose to $40^{\circ} \mathrm{C}$. After 1 day of treatment, the third fully expanded leaves of tall fescue were collected and stored at $-80^{\circ} \mathrm{C}$ for physiological and metabolic assays. Meantime, the chlorophyll (chl) $a$ fluorescence transient was recorded at 0 and 1 day after the treatment.

\section{Chlorophyll (chl) a Fluorescence Transient}

Chl $a$ fluorescence was determined by using a pulse-amplitude modulation (PAM) fluorometer (PAM 2500, Heinz Walz GmbH) with high time resolution $(10 \mu \mathrm{s})$. Each measurement was repeated for at least five times. Subsequently, the leaves were accommodated in the dark for $30 \mathrm{~min}$, and all measurements were taken using a saturating light intensity of $2000 \mu \mathrm{mol}$ photons $\mathrm{m}^{-2} \mathrm{~s}^{-1}$. The strong light pulses inducted chl $a$ fluorescence emission was measured subsequently and digitized between $10 \mu \mathrm{s}$ and $300 \mathrm{~ms}$ (Korres et al., 2003). The OJIP transients were then analyzed by using the JIP-test as described by Chen et al. (2013).

\section{The JIP-Test}

The JIP-test is a multi-parametric analysis of the OJIP transient according to Strasser et al. (2004). Chlorophyll fluorescence kinetics curve referred to the changing process from initial fluorescence intensity $F_{0}$ to a maximal intensity $F_{\mathrm{P}}$, and the dark-adapted oxygenic photosynthetic organisms show a OJIP rise when illuminated with high intensity actinic light. A typical JIP-test included four phrases: O-J (0.05-5 ms), J-P (5-50 ms), and I-P (50-1000 ms). Chlorophyll fluorescence kinetics curve provides valuable information on the magnitude of stress effects on photosynthesis function, and those changes in photochemistry can be deduced by original fluorescence measurements in JIP-test which is based on the energy flux in biofilm (Ni et al., 2012).

\section{Crude Enzyme Extraction}

To extract crude enzyme, about $0.2 \mathrm{~g}$ of fully expanded leaves were grounded by using ice-cooled mortar and pestle in $4 \mathrm{~mL}$ of $150 \mathrm{mM}, \mathrm{pH} 7.0$ sodium phosphate buffer (pre-cooled at $4^{\circ} \mathrm{C}$ ). The homogenate was transferred into $10 \mathrm{~mL}$ tubes and centrifuged for $20 \mathrm{~min}$ at $12,000 \mathrm{rpm}$ at $4^{\circ} \mathrm{C}$. The resulting supernatant was the crude enzyme for physiological assays.

\section{Determination of MDA Content}

The MDA content was determined by the thiobarbituric acid (TBA) method according to previous reports ( $\mathrm{Hu}$ et al., 2012; Fan et al., 2015). A $1 \mathrm{~mL}$ of crude enzyme solution was homogenized in $2 \mathrm{~mL} 0.5 \%(\mathrm{v} / \mathrm{v})$ TBA and $20 \%(\mathrm{v} / \mathrm{v})$ trichloroacetic acid. The mixture was incubated at $95^{\circ} \mathrm{C}$ for $30 \mathrm{~min}$ in a water bath, then cooled to room temperature $\left(25^{\circ} \mathrm{C}\right)$, and centrifuged at $12,000 \mathrm{rpm}$ for $10 \mathrm{~min}$ under $20^{\circ} \mathrm{C}$. The absorbance of the supernatant was determined at 523 and $600 \mathrm{~nm}$ with a spectrophotometer (UV2600, UNIC, Shanghai, China). MDA content was calculated with the following formula:

$$
\operatorname{MDA}\left(\mathrm{mol} \cdot \mathrm{g}^{-1} \mathrm{FW}\right)=\left[(\mathrm{OD} 532-\mathrm{OD} 600)^{*} \mathrm{~L}\right] /\left(\mathrm{l}^{*} \varepsilon^{*} \mathrm{FW}\right)
$$

where $\mathrm{L}$ indicates the volume of the extract solution, 1 indicates the thickness of cuvettes, $\varepsilon$ is the extinction coefficient of $155 \mathrm{mM}^{-1} \mathrm{~cm}$, and FW is the fresh weight of the leaves.

\section{Quantification of Electrolyte Leakage (EL)}

To determine the EL, about $0.15 \mathrm{~g}$ leaves were collected from the plants and washed three times with deionized water. Subsequently, the leaves were cut into $0.5 \mathrm{~cm}$ long fragments and placed in $50 \mathrm{~mL}$ centrifuge tubes filled with $25 \mathrm{~mL}$ deionized water. The test tubes were shaken for $24 \mathrm{~h}$ at room temperature and the initial conductivity (Ci) was determined by a conductance meter (JENCO-3173, Jenco Instruments, Inc., San Diego, CA, United States). Then the tube-fragments systems were autoclaved at $121^{\circ} \mathrm{C}$ for $15 \mathrm{~min}$ to completely release the electrolytes, and the conductivity of the incubation solution with killed tissues (Cmax) was measured after the solution had cooled down to room temperature (Bi et al., 2016). The relative EL was calculated by the following formula:

$$
\text { RelativeEL(\%) = Ci/Cmax*100\%. }
$$

\section{Antioxidant Enzyme Activity}

Activities of SOD and POD were determined according to methods described by Fan et al. (2015). SOD activity was 
measured by monitoring the inhibition of nitro blue tetrazolium (NBT) reduction with a spectrophotometer at $560 \mathrm{~nm} ; 100 \mu \mathrm{L}$ of crude enzyme solution was mixed into $2.9 \mathrm{~mL}$ reaction solution which consisted of $50 \mathrm{mM}$ sodium phosphate buffer ( $\mathrm{pH}$ 7.8), $60 \mu \mathrm{M}$ riboflavin, $195 \mathrm{mM}$ methionine, $3 \mu \mathrm{M}$ ethylenediamine tetraacetic acid (EDTA), and $1.125 \mathrm{mM}$ NBT; $3 \mathrm{~mL}$ reaction solution was regarded as the control. The mixture was illuminated under $4000 \mathrm{~lx}$ fluorescent lamp for $60 \mathrm{~min}$ for chromogenic reaction, and then transferred to darkness to stop the reaction. One unit of SOD activity was defined as the amount of enzyme that inhibits the NBT reduction by $50 \%$. The activity of SOD was calculated with the following formula: $\operatorname{SOD}\left(\mathrm{U} \cdot \mathrm{g}^{-1} \mathrm{FW}\right)=\left(\mathrm{A}_{\mathrm{CK}}-\mathrm{A}_{\text {treatment }}\right) /\left(0.5{ }^{*} \mathrm{~A}_{\mathrm{CK}}{ }^{*} \mathrm{FW}\right) . \mathrm{FW}$ is the fresh weight of the leaves. As for POD activity measurement, $50 \mu \mathrm{L}$ crude enzyme solution was added into $2.95 \mathrm{~mL}$ reaction solution containing $100 \mathrm{mM}$ sodium acetate-acetic acid buffer ( $\mathrm{pH} 5.0$ ), $0.25 \%$ guaiacol, and $0.75 \% \mathrm{H}_{2} \mathrm{O}_{2}$. Absorbance at $460 \mathrm{~nm}$ was recorded at per minute interval for $3 \mathrm{~min}$. A unit of POD activity was defined as the changes in absorbance at $460 \mathrm{~nm}$ per minute. The activity of POD was calculated with following formula: POD $\left(\mathrm{U} \cdot \mathrm{g}^{-1} \mathrm{FW}\right)=\triangle \mathrm{A} 460 / \mathrm{FW}$. FW is the fresh weight of the leaves.

\section{Fatty Acid Extraction and FAME Analysis}

The plant leaves $(0.3 \mathrm{~g})$ were grounded into fine powder using a mortar and pestle with liquid $\mathrm{N}_{2}$. The tissue powder was transferred to test tubes. Total lipid was then extracted using the method described by Mishra et al. (2015). Three milliliters of extraction solution [chloroform: methanol: water (1: $2: 0.8 ; \mathrm{v} / \mathrm{v} / \mathrm{v})]$ were added to each sample. The samples were vortexed for $20 \mathrm{~min}$ at room temperature. Then $50 \mu \mathrm{L}$ $2 \mathrm{mg} / \mathrm{mL}$ of heptadecanoic acid (C17: 0$)$ was added as an internal standard.

The corresponding fatty acid methyl esters (FAMEs) of fatty acids were prepared by transmethylation (Kumari et al., 2012). Transmethylation was carried out by adding $\mathrm{NaOH}(1 \%$, v/v in methanol; $1 \mathrm{~mL}$ ) in a $15 \mathrm{~mL}$ tube which contained extracted lipid followed by heating at $55^{\circ} \mathrm{C}$ for $15 \mathrm{~min}$. Thereafter methanolic $\mathrm{HCl}(5 \%, \mathrm{v} / \mathrm{v} ; 2 \mathrm{~mL})$ was added, and the mixture was further heated at $55^{\circ} \mathrm{C}$ for $15 \mathrm{~min}$. Then $3 \mathrm{~mL}$ of the ultrapure waterhexane mixture $(1: 2, \mathrm{v} / \mathrm{v})$ was added into the mixture solution. The derivative FAMEs were extracted with hexane three times, vacuumed dried, and finally dissolved in hexane $(200 \mu \mathrm{L})$.

The FAMEs samples were analyzed on GC-MS (Agilent 7890A/5975C, Agilent Technologies, Palo Alto, CA, United States). In brief, $1 \mu \mathrm{L}$ of the derivative solution was injected into a DB-5MS capillary $(30 \mathrm{~m} \times 0.25 \mathrm{~mm} \times 0.25 \mathrm{~mm}$, Agilent Technologies, Palo Alto, CA, United States). The total analysis time of GC-MS is nearly $80 \mathrm{~min}$ and the specific program is as follows: the initial temperature of GC oven was kept at $70^{\circ} \mathrm{C}$ for $2 \mathrm{~min}$. Then increased to $230^{\circ} \mathrm{C}$ with $3^{\circ} \mathrm{C} \mathrm{min}{ }^{-1}$ increment and finally maintained at $230^{\circ} \mathrm{C}$ for $10 \mathrm{~min}$. Thereafter, the temperature was increased to $270^{\circ} \mathrm{C}$ with $10^{\circ} \mathrm{C} \mathrm{min}{ }^{-1}$ increment and kept for $10 \mathrm{~min}$. Helium was used as the carrier gas, and the flow rate was set at $1 \mathrm{mg} \cdot \mathrm{mL}^{-1}$. The determination was carried out by electron impact ionization at $70 \mathrm{eV}$ in the full scan mode $(m / z 30-650)$. The samples were quantified against an internal standard (100 $\mu \mathrm{g}$ heptadecanoic acid), and the content of each fatty acid was expressed as a proportion of the total fatty acids present in the sample. The double bond index (DBI) was calculated by using the formula: index $=(16: 1)+(18: 1)$ $+2[(16: 2)+(18: 2)]+3$ (18: 3) (Larkindale and Huang, 2004). Parentheses indicate the proportion of the total fatty acid amount, which was composed of each fatty acid species.

\section{Quantitative RT-PCR (Q-PCR) Analysis}

Total RNA was isolated and purified by using Trizol reagent (Invitrogen, America). The first strand cDNA was synthesized from $2 \mu \mathrm{g}$ of total RNA with oligo (dT) 12-18 primer using cDNA synthesis kit (Fermentas, Canada) according to the operation manual. Gene-specific primers for quantitative RT-PCR are listed in Table 1. When designing the primers, we blast the reference genome of tall fescue against with Arabidopsis thaliana, and select the peculiar part of the homologous gene of tall fescue as the starting point and end point of the amplified fragment. The TUB gene was used as the internal reference in the Q-PCR reaction. The program for Q-PCR was $94^{\circ} \mathrm{C}$ for $3 \mathrm{~min}$, followed by 45 cycles of $94^{\circ} \mathrm{C}$ for the $20 \mathrm{~s}, 50-55^{\circ} \mathrm{C}$ for $20 \mathrm{~s}$, then $72^{\circ} \mathrm{C}$ for $30 \mathrm{~s}$, with a final elongation at $72^{\circ} \mathrm{C}$ for $7 \mathrm{~min}$. The experiment was performed on a chromo4 real-time detection system (MJ Research, Cambridge, MA, United States) using SYBR Green I to produce a fluorogenic intercalating dye. The data were normalized with the relative efficiency of each primer pair.

\section{Statistical Analysis}

Five biological replicates were used in all the experiments, all results were expressed as mean \pm SE (standard error).

TABLE 1 | Primer sequences used for Q-PCR analyses.

\begin{tabular}{|c|c|c|c|}
\hline Gene & Encoded & & Primers sequences $\left(5^{\prime}-3^{\prime}\right)$ \\
\hline \multirow[t]{2}{*}{ TUB } & & $\mathrm{F}$ & ATGCTICGTCTTATGCCC \\
\hline & & $\mathrm{R}$ & CTCTTGGTITGATGGTTGC \\
\hline \multirow[t]{2}{*}{$p s b A$} & D1 protein & $\mathrm{F}$ & GTATITATTATCGCCTTCATCG \\
\hline & & $\mathrm{R}$ & AGGACGCATAWWAAACG \\
\hline \multirow[t]{2}{*}{$p s b B$} & $\mathrm{CP} 47$ & $\mathrm{~F}$ & TAGGCGTAACGGTGGA \\
\hline & & $\mathrm{R}$ & AATATCTCGGAACAAGG \\
\hline \multirow[t]{2}{*}{$p s b C$} & CP43 & $\mathrm{F}$ & TAATACGGCTTATCCGAGTGAGTII \\
\hline & & $\mathrm{R}$ & TCTTGCCAAGGTTGTATGTCTाা \\
\hline \multirow[t]{2}{*}{$A C A C$} & Ctyl-CoA carboxylase & $\mathrm{F}$ & TCGTGTTGTTGTGAAGTCT \\
\hline & & $\mathrm{R}$ & TGTTCCATAAGCCGTAGTAG \\
\hline \multirow[t]{2}{*}{$F a b D$} & Malonyltransferase & $\mathrm{F}$ & CAGGATGCTTCAGATGCT \\
\hline & & $\mathrm{R}$ & CATAGTTACCAGGACACAGA \\
\hline \multirow[t]{2}{*}{ FabF } & $\beta$-Ketoacyl & $\mathrm{F}$ & ATGGTAAGCATCACAGTTCA \\
\hline & -ACP synthetase II & $\mathrm{R}$ & AGCACTATCACAGAGGAATG \\
\hline \multirow[t]{2}{*}{$\mathrm{FabH}$} & $\beta$-Ketoacyl & $\mathrm{F}$ & GATTGACAACCGAGTAGCA \\
\hline & -ACP synthetase III & $\mathrm{R}$ & CCACAGTCCATTGAGAAGG \\
\hline \multirow[t]{2}{*}{ Fabl } & $\beta$-Enoyl & $\mathrm{F}$ & GAAGGAAGTGCTGGAGTAA \\
\hline & -ACP reductase & $\mathrm{R}$ & TGAAGGAAGTTGCTGAGAC \\
\hline \multirow[t]{2}{*}{ FatA } & Acyl-ACP thioesterase & $\mathrm{F}$ & ATGGAAGAGCACAATACACT \\
\hline & & $\mathrm{R}$ & GAGGAAGCAGAGGAGGAA \\
\hline
\end{tabular}

$F$ and $R$ represent forward and reverse, respectively. 
The analysis of variance (ANOVA) was performed by using SPSS statistical software package (Ver.16.0, SPSS Inc., Chicago, IL, United States) and DPS v7.05. The graphs were produced using Origin 8.0 (Origin Lab Inc., Hampton, VA, United States). Means were separated using Duncan's multiple range tests at $P<0.05$ level of significance.

\section{RESULTS}

\section{Physiological Response to the Heat Stress}

As shown in Figure 1, high temperature increased both MDA and relative EL in two tall fescue genotypes. Under heat stress, MDA contents were 69.1 and $17.3 \%$ higher for sensitive "TF133" and tolerant "TF71" when compared to their controls, respectively. Similar results were also observed regarding relative EL values.
Relative EL in heat treated "TF133" and "TF71" was 32.5 and $27.9 \%$ higher than their respective controls.

\section{Changes in Antioxidant Activity Under Heat Stress}

There was a progressive decrease in SOD and POD activities during heat treatment for "TF133," but no obvious change in "TF71" when compared to the control. As shown in Figure 2, high temperature dramatically decreased the activities of SOD and POD by 12.50 and $28.47 \%$ in "TF133," respectively. It showed significantly different behaviors between heat-tolerant genotype and heat-sensitive genotype under the same high temperature.

\section{Changes in OJIP Transient Curves Under Heat Stress}

High temperature significantly affected the OJIP fluorescence transient of both tall fescue genotypes. OJIP transient curves
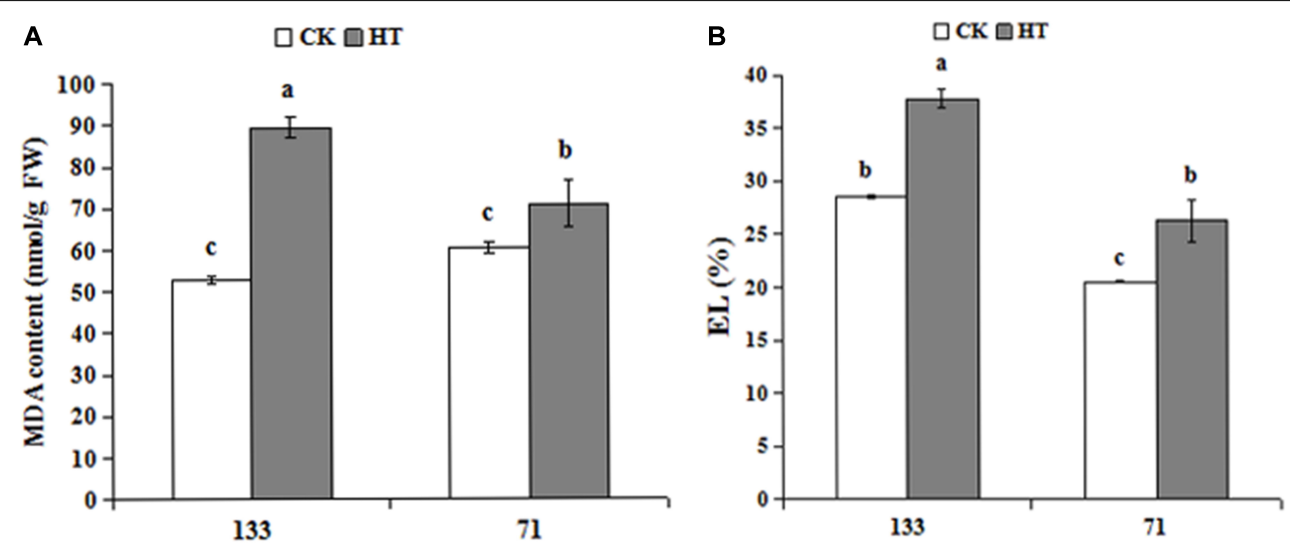

FIGURE 1 | Changes of MDA content (A) and relative EL (B) in tall fescue leaves in heat-sensitive genotype "TF133" and heat-tolerant genotype "TF71" under normal conditions or heat stress. CK was the control $\left(22 / 18^{\circ} \mathrm{C}\right.$ for light/dark), while HT was the heat treatment $\left(40 / 35^{\circ} \mathrm{C}\right.$ for light/dark). All the plants were treated for 1 day. Mean \pm SD were calculated from five biological repeats. Different letters indicated statistical difference significance at $P<0.05$ among the different treatments groups by Duncan's multiple range tests.
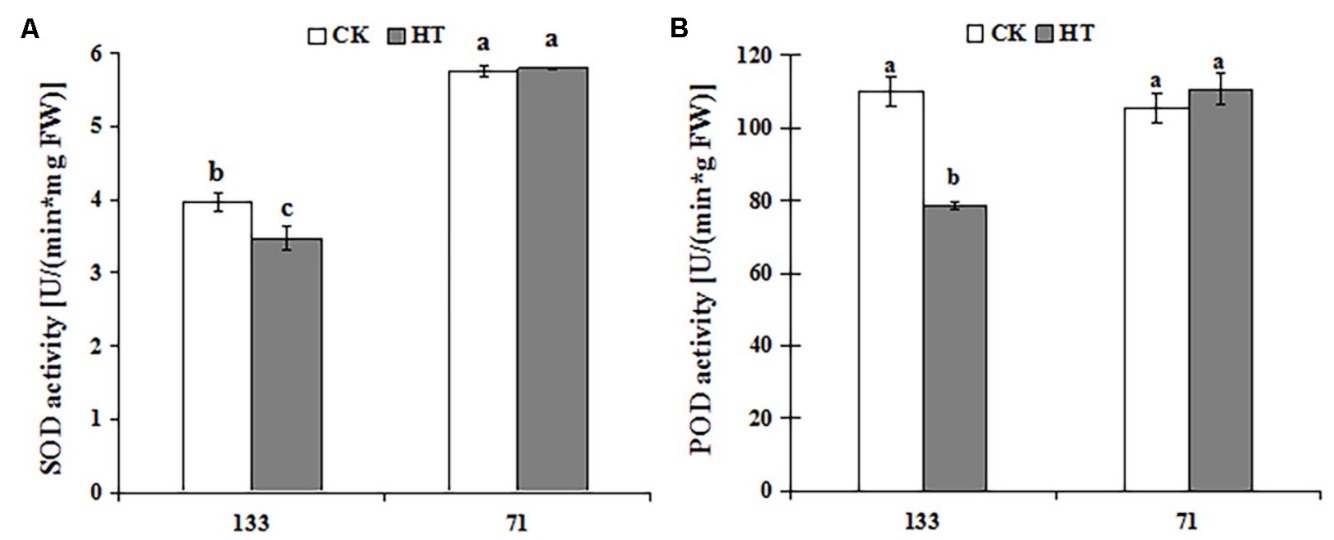

FIGURE 2 | Changes of SOD (A) and POD (B) activities in tall fescue leaves in heat-sensitive genotype "TF133" and heat-tolerant genotype "TF71" under normal conditions or heat stress. CK was the control $\left(22 / 18^{\circ} \mathrm{C}\right.$ for light/dark), while $\mathrm{HT}$ was the heat treatment $\left(40 / 35^{\circ} \mathrm{C}\right.$ for light/dark). All the plants were treated for 1 day. Mean \pm SD were calculated from five biological repeats. Different letters indicated statistical difference significance at $P<0.05$ among the different treatments groups by Duncan's multiple range tests. 


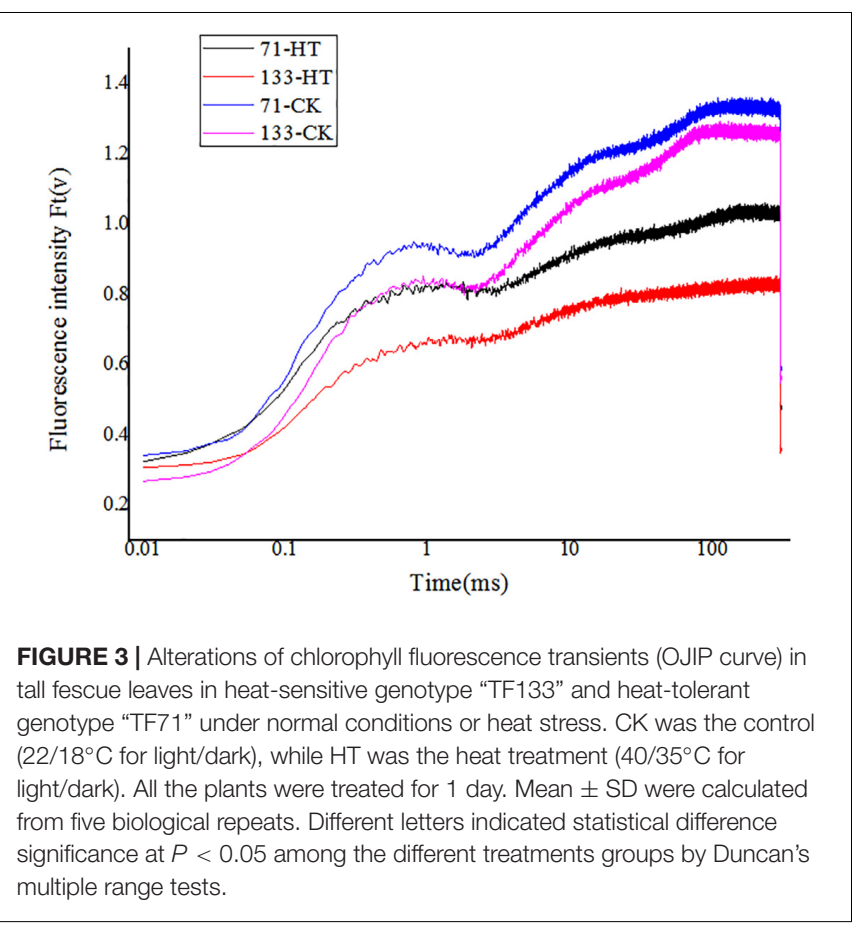

of control groups were higher than those of heat treatment groups (Figure 3). Furthermore, under normal condition, the OJIP transient curves exhibited higher levels for the heat-tolerant genotype versus the heat-sensitive genotype. High temperature led to more difference in OJIP between two genotypes.

To further investigate the structural alteration, functional parameters, and photosynthetic behaviors in different tall fescue genotypes under heat stress, the JIP-test was applied to analyze the value of OJIP transient curves. Basic fluorescence parameters including $F_{\mathrm{O}}, F_{\mathrm{K}}, F_{\mathrm{J}}, F_{\mathrm{I}}, F_{\mathrm{M}}$, and $M_{0}$ were extracted (Table 2 ). Both genotypes generally had a higher level of above basic parameters for under control regimes versus high temperature regimes, except $F_{\mathrm{O}}$ and $M_{0}$ which were lower under normal condition.

Marked differences in ABS/RC, TPo/RC, and ETo/RC were observed between control and high-temperature regimes. High temperature increased ABS/RC, but decreased ETo/RC for both tall fescue genotypes. In addition, TPo/RC was decreased just in heat-treated "TF133" plants, compared to nontreated plants. There were no differences in REo/RC between control and stress regimes for both genotypes. Parameters associated with quantum yield and efficiencies included $\varphi$ po, $\varphi$ Eo, Ro, and $\mathrm{yRC}$. Heat stress dramatically declined the value of $\varphi$ po and $\varphi$ Eo in both genotypes. In addition, it was noticed that the $\varphi$ po value in tolerant genotype was significantly higher than in sensitive genotype when grown under normal conditions. Similar results were also observed for $\mathrm{PI}_{\mathrm{ABS}}$ and $\mathrm{PI}_{\text {total }}$. There was no distinct difference in $\delta$ Ro and VRC between two genotypes either under normal condition or heat stress. However, high temperature increased

TABLE 2 | Photosynthetic parameters deduced by the JIP-test analysis of fluorescence transients.

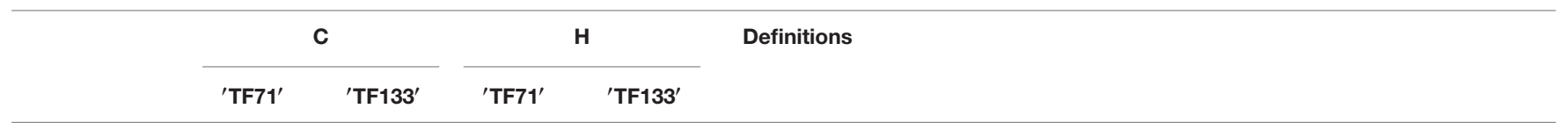

\section{Data extracted from the recorded OJIP fluorescence transient curves}

\begin{tabular}{|c|c|c|c|c|c|}
\hline$F_{0}=F_{20 \mu \mathrm{s}}$ & $0.35 \mathrm{a}$ & $0.28 \mathrm{c}$ & $0.35 \mathrm{a}$ & $0.31 b$ & Fluorescence at time t after onset of actinic illumination \\
\hline$F_{\mathrm{K}}$ & $0.84 a$ & $0.74 b$ & $0.75 b$ & $0.59 c$ & Fluorescence value at $300 \mu \mathrm{s}$ \\
\hline$F_{J}$ & $0.91 \mathrm{a}$ & $0.82 b$ & $0.79 c$ & $0.66 d$ & Fluorescence value at the J-step (2 ms) of OJIP \\
\hline$F_{1}$ & $1.23 \mathrm{a}$ & $1.15 b$ & $0.96 c$ & $0.78 d$ & Fluorescence value at the I-step (30 ms) of OJIP \\
\hline$F_{P}=F_{M}$ & $1.39 a$ & $1.31 b$ & $1.08 \mathrm{c}$ & $0.87 d$ & Fluorescence value at the peak of OJIP test \\
\hline$M_{0}$ & $1.88 \mathrm{~b}$ & $1.81 b$ & $2.34 a$ & $2.00 \mathrm{~b}$ & Approximate value of the initial slope of fluorescence transient curves \\
\hline
\end{tabular}

\section{Specific energy fluxes(per active PS II reaction center)}

\begin{tabular}{|c|c|c|c|c|c|}
\hline $\mathrm{ABS} / \mathrm{RC}$ & $4.65 b$ & $4.31 \mathrm{c}$ & $5.39 a$ & $4.78 b$ & Absorbed photon flux per RC \\
\hline $\mathrm{TPO} / \mathrm{RC}$ & $3.56 \mathrm{a}$ & $3.40 \mathrm{~b}$ & $3.60 a$ & $3.05 c$ & Trapped excitation flux (leading to $\mathrm{Q}_{\mathrm{A}}$ reduction) per $\mathrm{RC}$ \\
\hline $\mathrm{ETo} / \mathrm{RC}$ & $1.59 \mathrm{a}$ & $1.62 a$ & $1.30 \mathrm{~b}$ & $1.19 b$ & Electron transport flux (further than $\mathrm{Q}_{\mathrm{A}_{-}}$) per $\mathrm{RC}$ \\
\hline $\mathrm{REo} / \mathrm{RC}$ & $0.57 a$ & $0.56 a$ & $0.55 a$ & $0.48 \mathrm{a}$ & Electron transport reducing end electron acceptors at the PSI acceptor side, per RC \\
\hline
\end{tabular}

Quantum yields and efficiencies/probabilities

\begin{tabular}{|c|c|c|c|c|c|}
\hline$\varphi p o=T R o / A B S$ & $0.74 b$ & $0.79 a$ & $0.68 \mathrm{c}$ & $0.64 d$ & Maximum quantum yield for primary photochemistry, namely $F_{V} / F_{M}$ \\
\hline ÖEo = ETo/ABS & $0.34 \mathrm{a}$ & $0.37 a$ & $0.25 b$ & $0.24 b$ & Quantum yield of the electron transport flux from $Q_{A}$ to $Q_{B}$ \\
\hline$\delta R o=R E O / R C$ & $0.36 a b$ & $0.33 b$ & $0.41 \mathrm{ab}$ & $0.46 a$ & Quantum yield for reduction of end electron acceptor at the PSI acceptor side \\
\hline YRC & $0.18 a b$ & $0.19 a$ & $0.16 b$ & $0.17 \mathrm{~b}$ & probability that a PS II Chl molecule functions as RC \\
\hline
\end{tabular}

Performance Indexes (PI, combination of parameters)

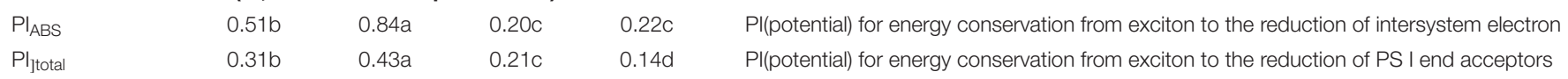

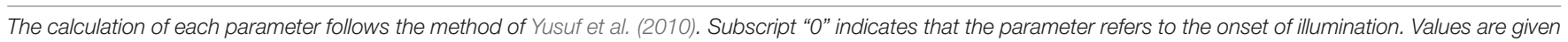

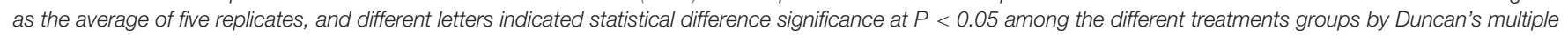
range tests. 
A

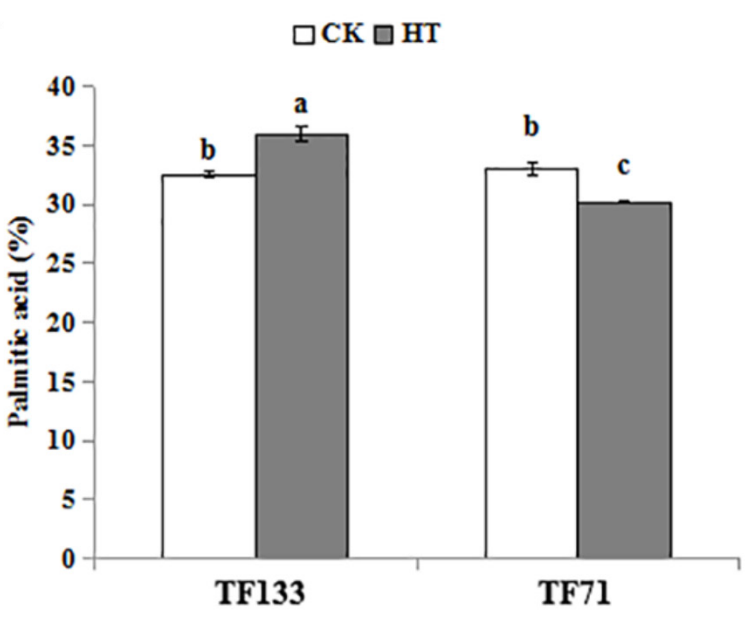

C

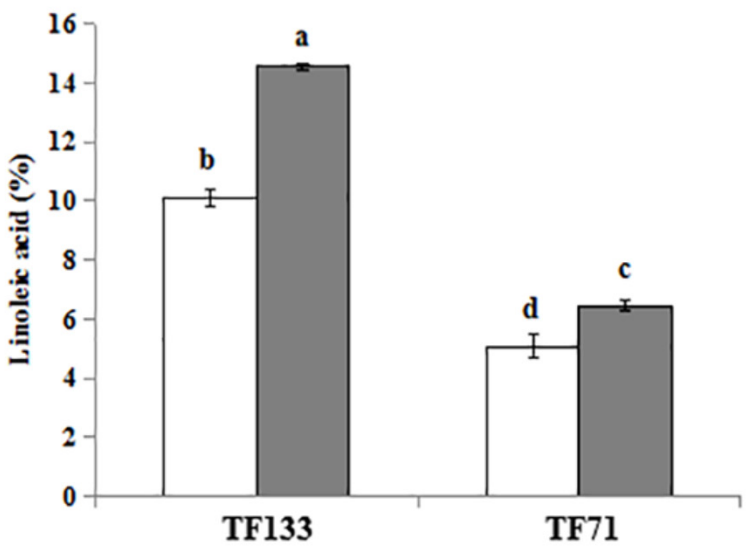

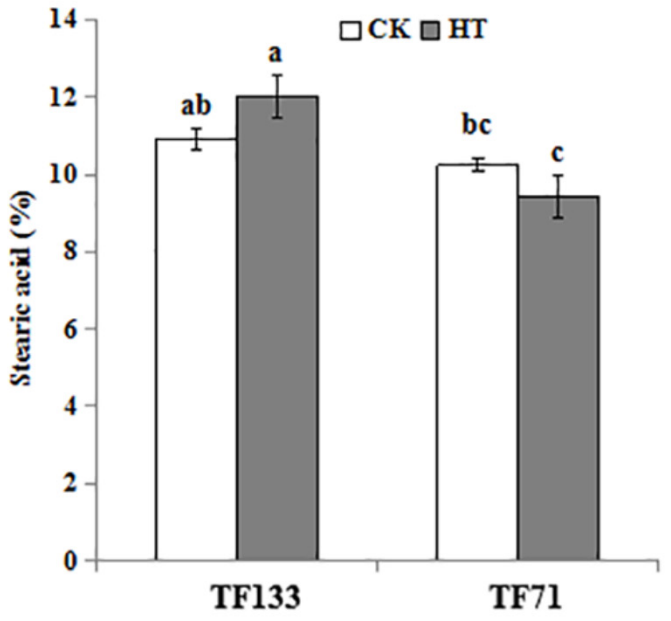

D

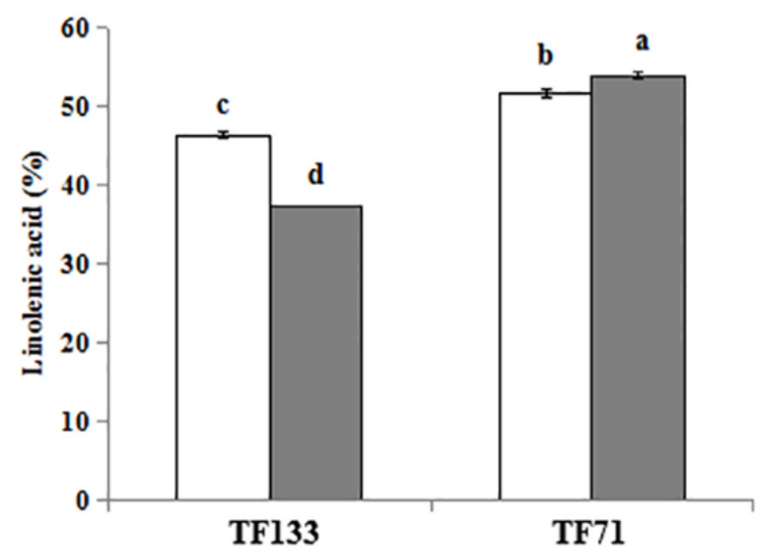

FIGURE 4 | Changes of four major fatty acids in tall fescue leaves in heat-sensitive genotype "TF133" and heat-tolerant genotype "TF71" under normal conditions or heat stress. (A) Palmitic acid. (B) Stearic acid. (C) Linoleic acid. (D) Linolenic acid. CK was the control $\left(22 / 18^{\circ} \mathrm{C}\right.$ for light/dark), while HT was the heat treatment $\left(40 / 35^{\circ} \mathrm{C}\right.$ for light/dark). All the plants were treated for 1 day. Mean $\pm \mathrm{SD}$ were calculated from five biological repeats. Different letters indicated statistical difference significance at $P<0.05$ among the different treatments groups by Duncan's multiple range tests.

the $\delta$ Ro whereas reduced the $\mathrm{rRC}$ values in both tall fescue genotypes.

\section{Changes in Fatty Acid Composition Under Heat Stress}

Four major fatty acids were identified and quantified by using GC-MS in this study. There were two SFAs and two UFAs, i.e., palmitic acid (C16: 0), stearic acid (C18: 0) and linoleic acid (C18: 2), linolenic acid (C18: 3), respectively. As shown in Figure 4, the palmitic acid content was 32.21 and $33.0 \%$ in "TF133" and "TF71" under control condition, respectively. However, after heat treatment, the percentage was increased to $35.99 \%$ in "TF133" but decreased to $30.22 \%$ in "TF71" (Figure 4A). High temperature modestly increased the stearic acid content from 10.92 to $12.00 \%$ in "TF133" and decreased the stearic acid accounted 10.24 to $9.42 \%$ of total fatty acid content in "TF71" after heat treatment (Figure 4B). Under high temperature, the linoleic acid content was significantly increased from 5.08 to 6.45 and 10.12 to $14.55 \%$ in "TF71" and "TF133," respectively (Figure 4C). Under control condition, the linolenic acid content was relatively higher in "TF71" than in "TF133." After heat stress, however, the linolenic acid level was significantly declined from 46.33 to $37.38 \%$ in "TF133," while moderately increased from 51.68 to $53.92 \%$ in "TF71" (Figure 4D).

Under control condition, there was no difference in unsaturation degree of fatty acids between the two genotypes. However, after heat stress, the unsaturation degree was significantly decreased to $52.01 \%$ in "TF133" but increased to $60.37 \%$ in "TF71" (Figure 5A). To determine the fatty acid composition, the UFA/SFA ratio was determined. Under control condition, no obvious difference in UFA/SFA ratio was observed between the two genotypes. However, after heat treatment, the ratio decreased by $16.8 \%$ in "TF133," while increased by $16.0 \%$ in "TF71" (Figure 5B), when compared to their controls, 

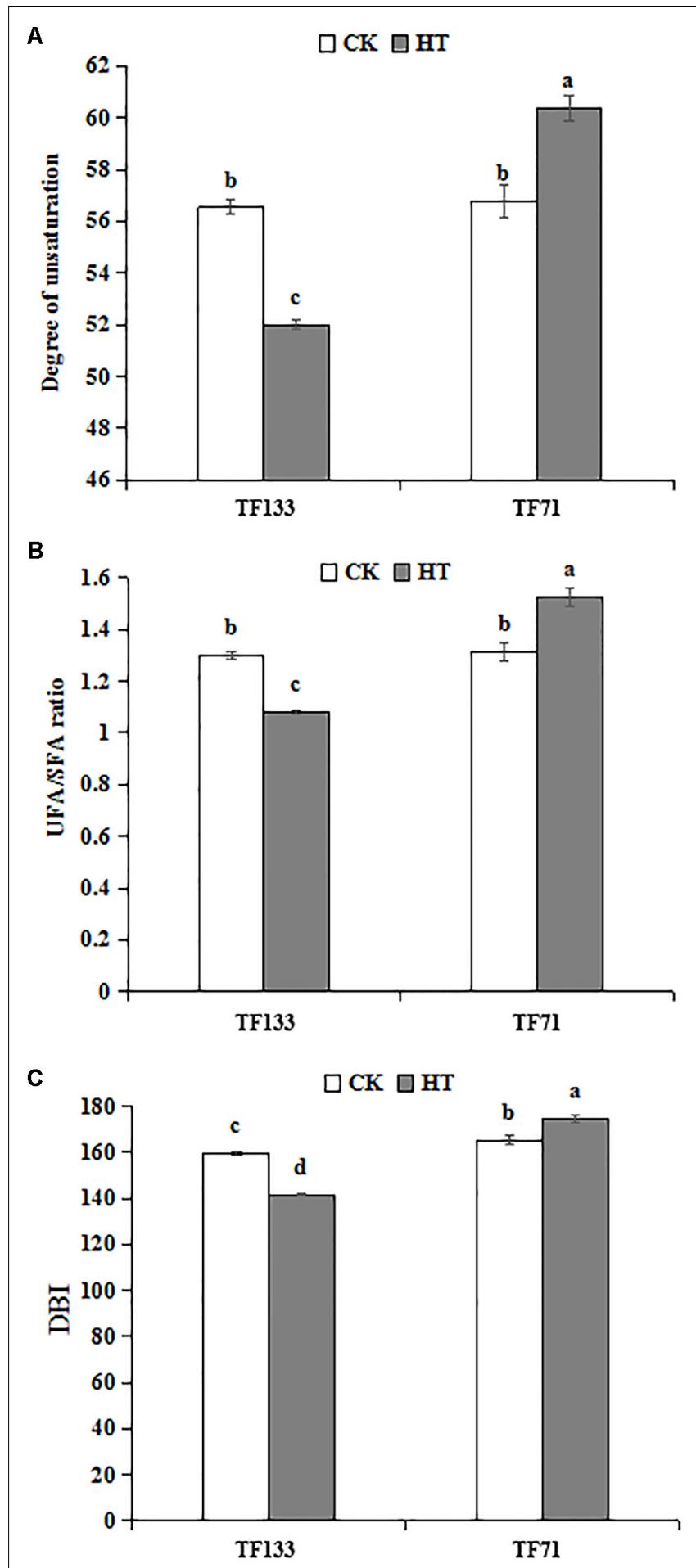

FIGURE $\mathbf{5}$ | Changes of degree of unsaturation (A), the ratio of UFA to SFA (B), and double bond index (DBI) (C) in tall fescue leaves in heat-sensitive genotype "TF133" and heat-tolerant genotype "TF71" under normal conditions or heat stress. CK was the control $\left(22 / 18^{\circ} \mathrm{C}\right.$ for light/dark), while $\mathrm{HT}$ was the heat treatment $\left(40 / 35^{\circ} \mathrm{C}\right.$ for light/dark). All the plants were treated for 1 day. Mean \pm SD were calculated from five biological repeats. Different letters indicated statistical difference significance at $P<0.05$ among the different treatments groups by Duncan's multiple range tests. respectively. As for DBI, high temperature significantly decreased it by $11.43 \%$ for "TF133" but increased by $5.7 \%$ in "TF71" (Figure 5C).

\section{Expression Profiles of Genes Related to Photosynthetic System and Fatty Acid Synthesis Pathway}

To investigate the gene expression pattern of photosynthetic system genes and fatty acid synthesis pathway in response to heat stress, three genes involved in the photosynthetic system and six genes involved in fatty acid synthesis pathway were analyzed by Q-PCR. High temperature significantly enhanced the gene transcription level of $P s b A$ compared to the control regime in both tall fescue genotypes (Figure 6). After heat treatment, the transcription level of $P s b B$ showed no obvious difference in "TF133," but a remarkable decrease in "TF71," when compared to their controls, respectively. The transcription level of $P s b C$ was reduced by heat stress in both genotypes. In addition, the abundance of PsbC was higher in "TF71" than "TF133" under both control and heat stress conditions. The expression of FabD was up-regulated by heat treatment in "TF133," but down-regulated in "TF71" (Figure 7). The similar trend was also observed for gene $\mathrm{FabH}$. In contrast, ACAC displayed downregulation in "TF133," but up-regulation in "TF71" after heat treatment, when compared to their respective controls. The expression of both $F a b I$ and $F a b F$ was significantly inhibited by high temperature in "TF71," whereas it showed no difference in "TF133," when compared to their controls, respectively. In addition, the transcription level of FatA significantly declined in both genotypes under heat treatment.

\section{DISCUSSION}

High temperature is one of the most detrimental environmental stresses, which can induce cell damage and constrain plant growth. The excess generation of ROS is one of the major consequence of heat stress, which subsequently induces cell membrane injury, damage the photosynthesis systems and PSII oxygen evolving complex and influence the protein synthesis (Sairam et al., 2000; Wahid and Close, 2007). Plant can tolerate heat stress by physical changes within the plant body and by creating signals for changing metabolism (Mirza et al., 2013). Cell membrane injury is related to the composition and content of fatty acids in the lipid bilayers of the membrane (Yordanov et al., 2000; Gigon et al., 2004). However, the relationship between the composition and saturation level of fatty acids and heat tolerance in different plant genotypes is still unknown.

The photosynthetic activity of chloroplast is considered to be the most thermo-sensitive cell function. In this study, high temperature declined the OJIP transient curve level at both tall fescue genotypes, and to a greater extent in "TF133." Abundant information can be revealed by the OJIP fluorescence transient, and it was used to determine the parameters through JIPtest (Krause et al., 2014). The $F_{0}$ is the level of fluorescence emission when all the primary quinone acceptors $\left(\mathrm{Q}_{\mathrm{A}}\right)$ were in oxidized state after dark adaptation. The $F_{0}$ rise of leaves results 


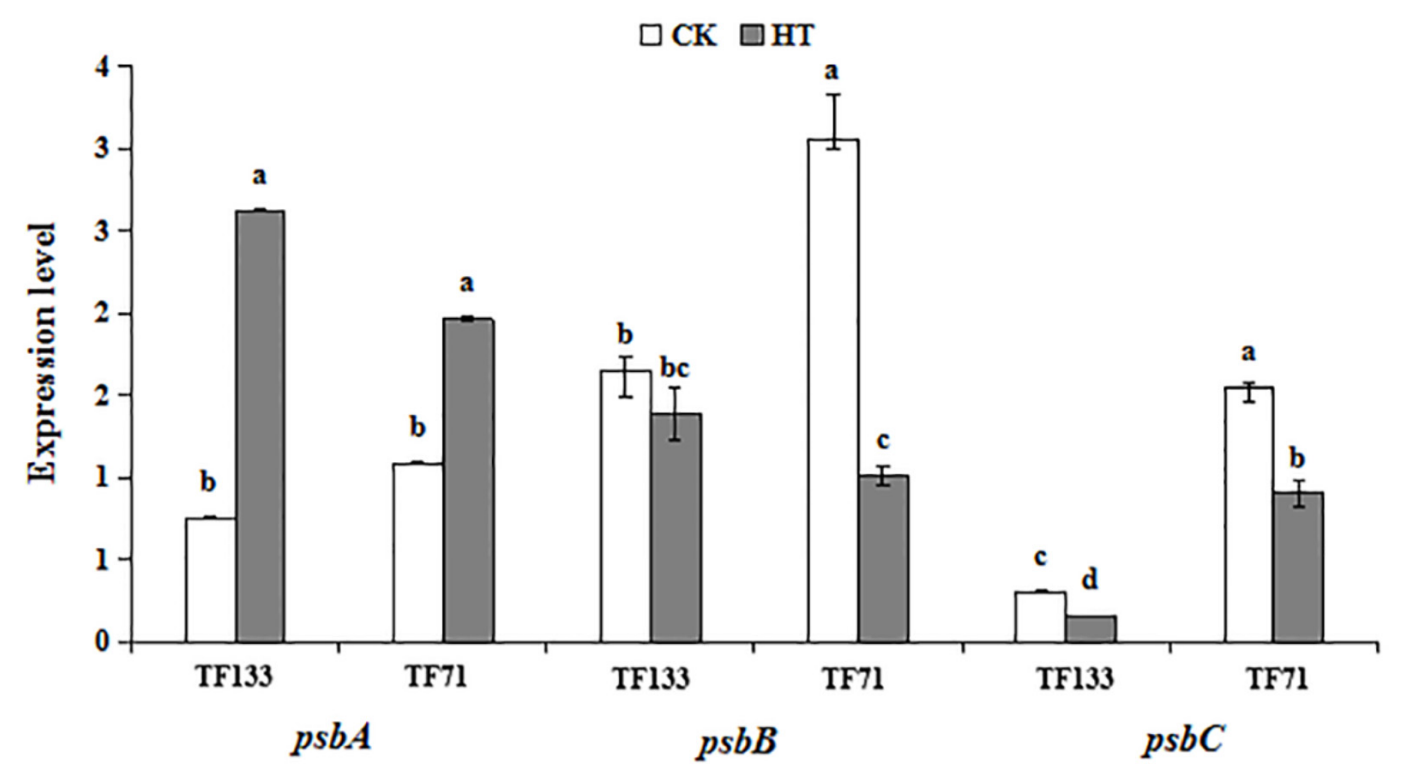

FIGURE 6 | The effects of heat treatments on gene expression of PsbA, PsbB, and Psbc in tall fescue leaves in heat-sensitive genotype "TF133" and heat-tolerant genotype "TF71" under normal conditions or heat stress.CK was the control $\left(22 / 18^{\circ} \mathrm{C}\right.$ for light/dark), while $\mathrm{HT}$ was the heat treatment (40/35 ${ }^{\circ} \mathrm{C}$ for light/dark). All the plants were treated for 1 day. Mean \pm SD were calculated from five biological repeats. Different letters indicated statistical difference significance at $P<0.05$ among the different treatments groups by Duncan's multiple range tests.

from the physical separation of the PS II reaction centers from their associated pigment antennae under heat stress, resulting in blocked energy transfer to the PS II traps and a decrease of the quantum efficiency of PS II (Briantais et al., 1996; Krause et al., 2014). The total performance index $\mathrm{PI}_{\text {total }}$ is the most general parameter in the JIP-test under stress conditions. It reflects the changes in intersystem electron and the energy conservation from exciton to the reduction of PSI end acceptors (Yusuf et al., 2010; Stefanov et al., 2011). The parameters $\varphi$ po, öEo, and $\delta$ Ro were used to assess the impairment of components in PSII and investigate more details (Chen et al., 2013). The $\varphi$ po and öEo values were remarkably changed while the $\delta$ Ro was slightly altered under heat stress, and the treatment with high temperature significantly decreased the behavior of $\varphi$ po and öEo in tall fescue. Thus, the results suggested that the behaviors of PS II on both electron donor side and acceptor side are blocked under heat stress and PSI was less damaged than PSII (Apostolova and Dobrikova, 2010; Zushi et al., 2012). Furthermore, $\mathrm{PI}_{\text {total }}$ and $\mathrm{PI}_{\mathrm{ABS}}$ were higher in non-treated than heat-treated plants, and to a higher extent in "TF133." This result confirmed that in order to protect the plant from the harsh environmental condition, excess excitation energy was transformed into heat dissipation so as to keep the balance between energy absorption and utilization (Perales-Vela et al., 2007).

The alteration of photosynthesis was also related to the changes in gene expression patterns. CP47 ( $p s b B$ encoded protein) and $\mathrm{CP} 43$ ( $p s b C$ encoded protein) are the intrinsic transmembrane proteins, which located in the reaction center of PS II. Previous studies showed that the light harvesting antenna would be decoupled from the RC, and the damaged D1 protein would be cleavaged under high temperature
(Yoshioka et al., 2006). Both of the transcription and translation levels of $p s b A$ will decrease under heat stress, meanwhile reducing the transcription product mRNA of $p s b A$ and D1 protein content (Yang et al., 2013). Moreover, the decrease of CP43 and CP47 would lead to a reduction in active RC and result in inefficient energy utilization (Vani et al., 2001). In this study, the expression of $p s b A$, which encoding for D1 protein in the core of $\mathrm{RC}$, is higher in heat-treated plants than in the controls. Its up-regulation is favorable for PSII RC against high temperature and confirmed that heat stress improves the susceptibleness of this photosynthetic organs (Takahashi et al., 2004).

Malondialdehyde and EL were valid indicators to show the degree of cellular injury caused by environmental stress (Hernández and Almansa, 2002). Furthermore, MDA is a final decomposition product of lipid peroxidation (Monteiro et al., 2008). The current results suggested that high temperature induced lipid peroxidation and plasma membrane permeability increases. The dismutation of converting $\mathrm{O}_{2}^{-}$to $\mathrm{H}_{2} \mathrm{O}_{2}$ is important in defense ROS, which is catalyzed by SOD. Then $\mathrm{H}_{2} \mathrm{O}_{2}$ was removed by POD to regulate the relatively stable level of $\mathrm{H}_{2} \mathrm{O}_{2}$ (Mansoor, 2013). In the present study, the activities of both SOD and POD in “TF71" are higher than "TF133," suggested that the induction of antioxidant enzyme activities is closely contact with increased environmental stress (Ashraf, 2009) and increasing antioxidant enzyme activity to scavenge ROS will enhance plant heat resistant. In summary, the abilities of "TF71" is better than "TF133" in maintaining normal photosynthesis and cell membrane stability to protecting heat stress.

To further explore the possible heat-resistance mechanism underlying fatty acid, the lipid composition was analyzed in this 
A

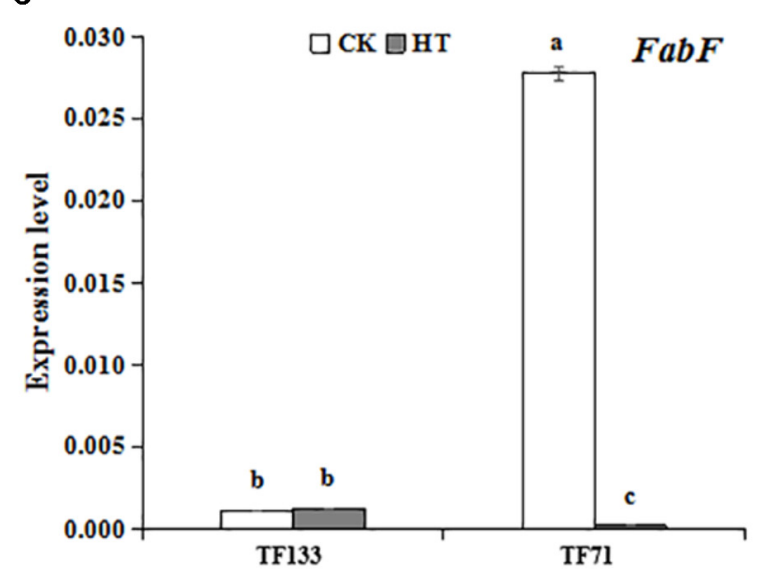

E

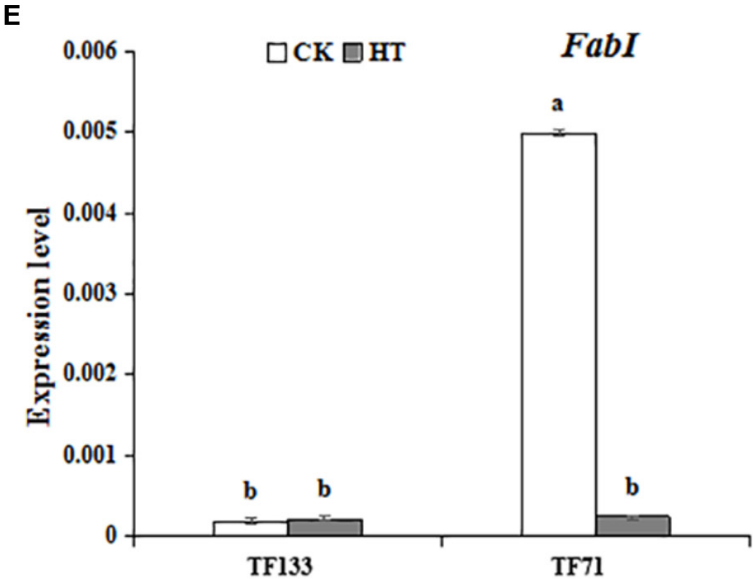

B

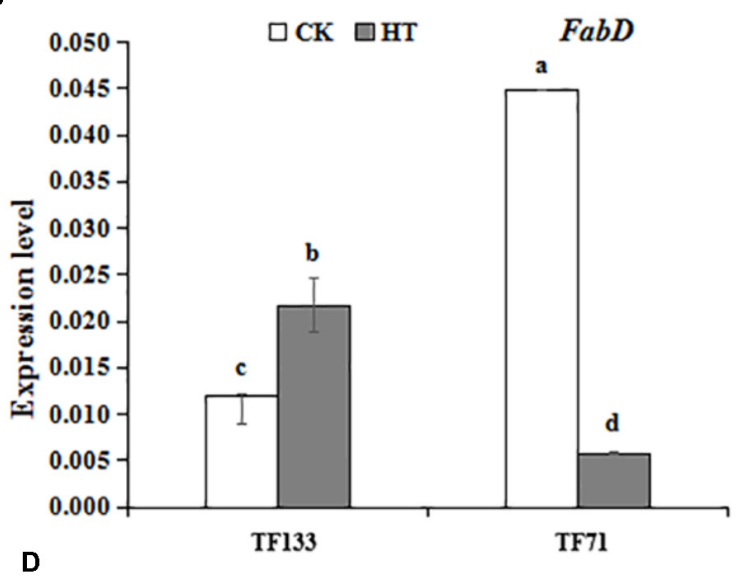

D

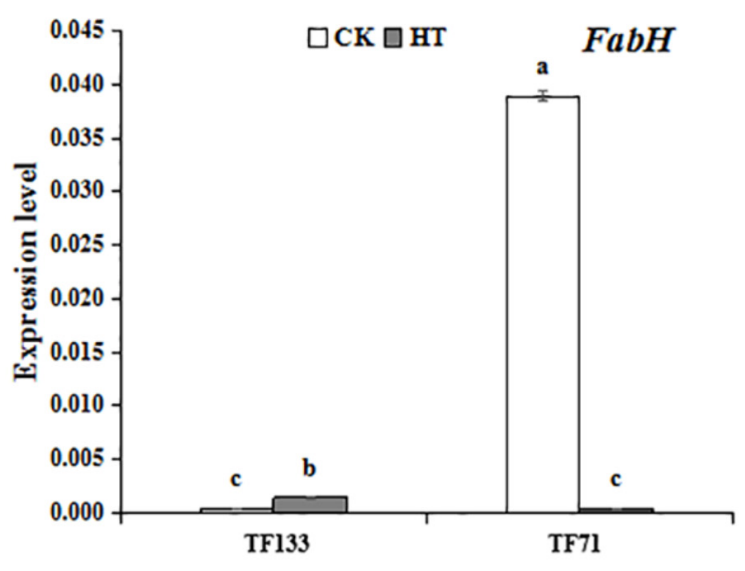

F

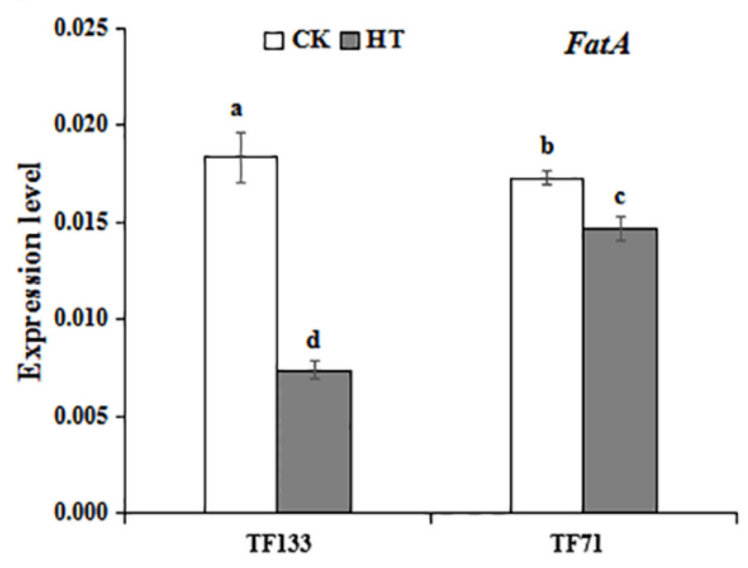

FIGURE 7 | The effects of heat treatments on gene expression of (A) ACAC (encoding fore actyl-CoA carboxylase), (B) FabD (encoding fore malonyltransferase), (C) FabF (encoding fore $\beta$-ketoacyl-ACP synthetase II), (D) FabH (encoding fore $\beta$-ketoacyl-ACP synthetase III), (E) Fabl (encoding fore $\beta$-enoyl-ACP reductase), and (F) FatA (encoding fore acyl-ACP thioesterase) in tall fescue leaves in heat-sensitive genotype "TF133" and heat-tolerant genotype "TF71" under normal conditions or heat stress. CK was the control $\left(22 / 18^{\circ} \mathrm{C}\right.$ for light/dark), while $\mathrm{HT}$ was the heat treatment $\left(40 / 35^{\circ} \mathrm{C}\right.$ for light/dark). All the plants were treated for 1 day. Mean $\pm \mathrm{SD}$ were calculated from five biological repeats. Different letters indicated statistical difference significance at $P<0.05$ among the different treatments groups by Duncan's multiple range tests.

study. Under heat stress, "TF71" maintained a relatively high level of UFA and was less affected by the thermal damage. It may be a protective mechanism in "TF71" to adapt to heat stress.
The results of fatty acid composition indicated that unsaturated membrane lipid played an important role in improving plant heat resistance (Alvarezordóñez et al., 2008; Wang et al., 2013). DBI 
is an indicator for evaluating unsaturation level of fatty acids (Zhong et al., 2011). Under heat condition, the value of DBI declined in "TF133," while it increased in "TF71." This trend of "TF133" under heat stress is consistent with the change in Arabidopsis at $30^{\circ} \mathrm{C}$ (Li et al., 2015). Similar results were observed in the parameters of UFA/SFA ratio and degree of unsaturation. These results further suggested that relatively higher unsaturation degree of total lipid may contribute to the greater heat resistance in "TF71."

The expression pattern of fatty acid synthesis related genes was also investigated. It is the carboxylation of acetyl-CoA that limited the rate of fatty acid synthesis. So that the transcription of acetyl-CoA carboxylase ( $A C A C$ encoded a protein) is closely linked with the later fatty acid synthesis. Malonyltransferase (FabD encoded a protein) is a key enzyme for the synthesis of fatty acids. It is a thiolase that catalyzes the initial step of the fatty acid synthesis, catalyzing the formation of malonyl-ACP with malonyl-CoA and ACP as substrates (Prigge et al., 2003). Malonyl-ACP plays an important role in the synthesis of type II fatty acids, which is an important substrate for the synthesis of palmitic acid (Eckhardt et al., 2013). $\beta$-ketoacyl-ACP synthetase II (KAS II) (FabF encoded a protein), KAS III (FabH encoded a protein), and $\beta$-enoyl-ACP reductase ( $F a b I$ encoded a protein) are involved in fatty acid elongation. At present, there are three kinds of $\beta$-ketoacyl-ACP synthetase (KAS), which is KAS I, KAS II, and KAS III. KAS I catalyzes the condensation of 4 carbon to 14 carbonated acyl-ACP; KAS II catalyzes the condensation of 14 carbon and 16 carbonated acyl-ACP and determines the ratio of (16 carbon fatty acid) / (18 carbon fatty acid), while KAS III catalyzes the condensation of malonyl-ACP with acetyl-ACP and the subsequent one to two cycles. $\beta$-enoyl-ACP reductase catalyzes the last step of each cycle and generates an acyl-ACP with a 2-base increase (Lu, 2000).

In the present study, under normal condition, the transcription of ACAC in "TF133" is much higher than that in "TF71." Meanwhile, the genes involved in long-chain fatty acid synthesis show an opposite trend. After heat stress, the transcription of ACAC decreased in "TF133" but still maintained a relatively high transcription level compared to that in "TF71," even though the transcription in TF71 increased significantly. Then, the transcription of fatty acid synthesis genes has no significant change in "TF133," but the transcription in "TF71" decreased to the same level with "TF133." The results indicated that plant regulate the transcriptional balance between substrates synthesis and fatty acid synthesis to maintain a stable fatty acid content under different environment. Specific regulation is just like that keeping a lower transcription level of fatty acid synthesis genes when substrate is abundant, and maintaining a higher transcription when the substrate is low. This transcriptional regulation result in no significant change in SFA under heat stress in both genotypes. The results also showed to some extent that the relationship between fatty acid content and heat resistance is not as close as fatty acid composition.

Acyl-ACP thioesterase A (FatA encoded a protein) catalyzes the termination of FAS cycling. It determines the length and saturation level of free fatty acid transport in and out of plant plastids. In plant cell, SFA are catalyzed by the type II FAS system in the plasmid, and the final products are only C16: 0ACP and C18: 0-ACP. Most C18: 0-ACP produced by elongation is desaturated by the stearoyl-ACP desaturase. The resulting C18: 1-ACP can enter the prokaryotic glyceroipid pathway or be hydrolyzed by FatA for export from the plastid (Vigh et al., 1993; Salas and Ohlrogge, 2002; Libeisson et al., 2010). The C18:1 diffused from plastid was transported to the endoplasmic reticulum and then be synthesized other glycerides. In the present study, the transcription of FatA significantly reduced in "TF133" after heat stress. This may cause a reduction in the hydrolysis and release of C18: 1-ACP, further affect the membrane lipid glyceride synthesis. The changes of PUFA under high temperature need to be further studied. According to the research results in Arabidopsis under high temperature of $\mathrm{Li}$, the possible reason for this change is that the ER-based $\omega-6$ desaturase responsible for the conversion of C18:1 to C18:2 was up-regulated at high temperature, concurrent with decreased proportion of C18:3 (Li et al., 2015).

In brief, the degree of membrane unsaturation is one determining factor in adaptation to high temperature stress. Our results in this study highlight the significance of changes in fatty acid composition under heat stress. At high temperature, tall fescue controls the equilibrium rate of substrate synthesis and fatty acid synthesis, so as to maintain the stability of fatty acid content while up-regulating the UFA to maintain good fluidity in "TF71." Furthermore, this regulation helps to maintain the normal physiological characteristics of organisms in "TF71" and may contribute to the greater heat resistance.

\section{CONCLUSION}

The mechanism in tall fescue response to heat stress is complex. Superior high-temperature resistance in "TF71" might be attributed to its better response to antioxidant metabolism, PS II, and improved proportion of UFA or its controlling the equilibrium ratio of UFA/SFA. Together, they were jointly conducive to membrane stability, and therefore enhanced the adaptation to high temperature in tall fescue.

\section{AUTHOR CONTRIBUTIONS}

JF and HL designed the research. LH carried out the experiments, analyzed the data, and wrote the manuscript. $\mathrm{AB}$ and $\mathrm{ZH}$ assisted with doing the experiments. JF, HL, and EA helped to draft the manuscript and revise the manuscript. All authors read and approved the final manuscript.

\section{FUNDING}

This research was funded by the National Natural Science Foundation of China (Nos. 31201653, 31470363, and 3140 1915). 


\section{REFERENCES}

Alvarezordóñez, A., Fernández, A., López, M., Arenas, R., and Bernardo, A. (2008). Modifications in membrane fatty acid composition of Salmonella typhimurium in response to growth conditions and their effect on heat resistance. Int. J. Food Microbiol. 123, 212-219. doi: 10.1016/j.ijfoodmicro.2008. 01.015

Apostolova, E. L., and Dobrikova, A. G. (2010). "Effect of high temperature and UV-A radiation on photosystem II," in Handbook of Plant and Grop Stress, ed. M. Pessarakli (Boca Raton, FL: CRC Press).

Ashraf, M. (2009). Biotechnological approach of improving plant salt tolerance using antioxidants as markers. Biotechnol. Adv. 27, 84-93. doi: 10.1016/j. biotechadv.2008.09.003

Bi, A., Fan, J., Hu, Z., Wang, G., and Erick, A. (2016). Differential acclimation of enzymatic antioxidant metabolism and photosystem ii photochemistry in tall fescue under drought and heat and the combined stresses. Front. Plant Sci. 7:453. doi: 10.3389/fpls.2016.00453

Briantais, J. M., Dacosta, J., Goulas, Y., Ducruet, J. M., and Moya, I. (1996). Heat stress induces in leaves an increase of the minimum level of chlorophyll fluorescence, fo: a time-resolved analysis. Photosynth. Res. 48, 189-196. doi: 10.1007/bf00041008

Bush, L., and Fannin, F. F. (2009). Tall Fescue for the Twenty-First Century. Washington, DC: American Society of Agronomy.

Busheva, M., Tzonova, I., Stoitchkova, K., and Andreeva, A. (2012). Heat-induced reorganization of the structure of photosystem ii membranes: role of oxygen evolving complex. J. Photochem. Photobiol. B 117, 214-221. doi: 10.1016/j. jphotobiol.2012.10.004

Chen, K., Chen, L., Fan, J., and Fu, J. (2013). Alleviation of heat damage to photosystem ii by nitric oxide in tall fescue. Photosynth. Res. 116, 21-31. doi: 10.1007/s11120-013-9883-5

Cushman, J. C., and Bohnert, H. J. (2000). Genomic approaches to plant stress tolerance. Curr. Opin. Plant Biol. 3, 117-124.

Cyril, J., Powell, G. L., Duncan, R. R., and Baird, W. V. (2002). Changes in membrane polar lipid fatty acids of seashore paspalum in response to low temperature exposure. Crop Sci. 42, 2031-2037. doi: 10.2135/cropsci2002. 2031

Eckhardt, T. H., Skotnicka, D., Kok, J., and Kuipers, O. P. (2013). Transcriptional regulation of fatty acid biosynthesis in lactococcus lactis. J. Bacteriol. 195, 1081-1089. doi: 10.1128/jb.02043-12

Fan, J., Ren, J., Zhu, W. I., Amombo, E., Fu, J., and Chen, L. (2015). Antioxidant responses and gene expression in bermudagrass under cold stress. J. Am. Soc. Hortic. Sci. 139, 699-705. doi: 10.1093/jxb/eru373

Georgieva, K. (1999). Some mechanisms of damage and acclimation of the photosynthetic apparatus due to high temperature. Bulg J. plant Physiol. 25, 89-100. doi: 10.1016/j.plaphy.2015.07.009

Gigon, A., Matos, A. R., Laffray, D., Zuilyfodil, Y., and Phamthi, A. T. (2004). Effect of drought stress on lipid metabolism in the leaves of Arabidopsis thaliana (ecotype columbia). Ann. Bot. 94, 345-351. doi: 10.1093/aob/mch150

Hernández, J. A., and Almansa, M. S. (2002). Short-term effects of salt stress on antioxidant systems and leaf water relations of pea leaves. Physiol. Plant. 115, 251-257. doi: 10.1034/j.1399-3054.2002.1150211.x

Hoagland, D. R., and Arnon, D. I. (1937). The water-culture method for growing plants without soil. Calif. Agric. Exp. Stn. Circ. 347, 357-359.

Hu, L., Li, H., Pang, H., and Fu, J. (2012). Responses of antioxidant gene, protein and enzymes to salinity stress in two genotypes of perennial ryegrass (Lolium perenne) differing in salt tolerance. J. Plant Physiol. 169, 146-156. doi: 10.1016/ j.jplph.2011.08.020

Huang, B., Liu, X., and Xu, Q. (2001). Supra-optimal soil temperatures induced oxidative stress in leaves of creeping bentgrass cultivars differing in heat tolerance. Crop Sci. 41, 430-435. doi: 10.2135/cropsci2001.412430x

Janila, P., Pandey, M. K., Shasidhar, Y., Variath, M. T., Sriswathi, M., Khera, P., et al. (2016). Molecular breeding for introgression of fatty acid desaturase mutant alleles (ahFAD2A and ahFAD2B) enhances oil quality in high and low oil containing peanut genotypes. Plant Sci. 242, 203-213. doi: 10.1016/j.plantsci. 2015.08.013

Knight, H., and Knight, M. R. (2001). Abiotic stress signaling pathways: specificity and cross-talk. Trends Plant Sci. 6, 262-267. doi: 10.1016/s1360-1385(01) 01946-x
Korres, N. E., Froud-Williams, R. J., and Moss, S. R. (2003). Chlorophyll fluorescence technique as a rapid diagnostic test of the effects of the photosynthetic inhibitor chlorotoluron on two winter wheat cultivars. Ann. Appl. Biol. 143, 53-56. doi: 10.1111/j.1744-7348.2003. 00053.x

Kotak, S., Larkindale, J., Lee, U., Von, K. P., Vierling, E., and Scharf, K. D. (2007). Complexity of the heat stress response in plants. Curr. Opin. Plant Biol. 10, 310-316. doi: 10.1016/j.pbi.2007.04.011

Krause, G. H., Winter, K., Krause, B., and Virgo, A. (2014). Light-stimulated heat tolerance in leaves of two neotropical tree species, Ficus insipida and Calophyllum longifolium. Funct. Plant Biol. 42, 42-51.

Kumari, P., Bijo, A. J., Mantri, V. A., Reddy, C. R., and Jha, B. (2012). Fatty acid profiling of tropical marine macroalgae: an analysis from chemotaxonomic and nutritional perspectives. Phytochemistry 86, 44-56. doi: 10.1016/j.phytochem. 2012.10.015

Larkindale, J., and Huang, B. (2004). Changes of lipid composition and saturation level in leaves and roots for heat-stressed and heat-acclimated creeping bentgrass (Agrostis stolonifera). Environ. Exp. Bot. 51, 57-67. doi: 10.1016/ s0098-8472(03)00060-1

Li, Q., Zheng, Q., Shen, W., Cram, D., and Fowler, D. B. (2015). Understanding the biochemical basis of temperature-induced lipid pathway adjustments in plants. Plant Cell 27, 86-103. doi: 10.1105/tpc.114.134338

Libeisson, Y., Shorrosh, B., Beisson, F., Andersson, M. X., and Arondel, V. (2010). Acyl-lipid metabolism. Arabidopsis Book 8:e0133. doi: 10.1199/tab.0133

Liu, D., Zhao, S., Gao, R., Zhang, Z., Jiang, C., and Liu, Y. (2002). Response of Plants Photosynthesis to Higher Temperature. Harbin: Bulletin of Botanical Research.

Liu, X., and Huang, B. (2000). Heat stress injury in relation to membrane lipid peroxidation in creeping bentgrass. Crop Sci. 40, 503-510. doi: 10.2135/ cropsci2000.402503x

Lu, S. F. (2000). Biosynthesis and Gene Engineering of Plant Fatty Acids. Beijing: Chinese Bulletin of Botany.

Mansoor, S. (2013). Effect of heat stress on lipid peroxidation and antioxidant enzymes in mung bean (Vigna radiata 1) seedlings. Afr. J. Biotechnol. 12, 3196-3203. doi: 10.5897/AJB12.2808

Mirza, H., Kamrun, N., Mahabub, A. M., Rajib, R., and Masayuki, F. (2013). Physiological, biochemical, and molecular mechanisms of heat stress tolerance in plants. Int. J. Mol. Sci. 14, 9643-9684. doi: 10.3390/ijms14059643

Mishra, A., Patel, M. K., and Jha, B. (2015). Non-targeted metabolomics and scavenging activity of reactive oxygen species reveal the potential of Salicornia brachiata, as a functional food. J. Funct. Foods 13, 21-31. doi: 10.1016/j.jff.2014. 12.027

Monteiro, M. S., Santos, C., Soares, A. M. V. M., and Mann, R. M. (2008). Assessment of biomarkers of cadmium stress in lettuce. Ecotoxicol. Environ. Saf. 72, 811-818. doi: 10.1016/j.ecoenv.2008.08.002

Ni, L., Acharya, K., Hao, X., Li, S., Li, Y., and Li, Y. (2012). Effects of artemisinin on photosystem ii performance of Microcystis aeruginosa, by in vivo chlorophyll fluorescence. Bull. Environ. Contam. Toxicol. 89, 1165-1169. doi: 10.1007/s00128-012-0843-0

Pagliano, C., Chimirri, F., Saracco, G., Marsano, F., and Barber, J. (2011). One-step isolation and biochemical characterization of a highly active plant PSII monomeric core. Photosynth. Res. 108, 33-46. doi: 10.1007/s11120-0119650-4

Peng, Y., Huang, B. R., Li-Xin, X. U., and And, L. I. (2013). Heat stress effects on osmotic potential, membrane fatty acid composition and lipid peroxidation content of two kentucky bluegrass cultivars differing in drought tolerance. Acta Hortic. Sin. 40, 971-980.

Perales-Vela, H. V., González-Moreno, S., Montes-Horcasitas, C., and Cañizares-Villanueva, R. O. (2007). Growth, photosynthetic and respiratory responses to sub-lethal copper concentrations in Scenedesmus incrassatulus, (chlorophyceae). Chemosphere 67, 2274-2281. doi: 10.1016/j.chemosphere. 2006.11.036

Pospíšil, P., and Tyystjärvi, E. (1999). Molecular mechanism of high-temperatureinduced inhibition of acceptor side of photosystem ii. Photosynth. Res. 62, 55-66. doi: 10.1023/A:1006369009170

Prigge, S. T., He, X., Gerena, L., Waters, N. C., and Reynolds, K. A. (2003). The initiating steps of a type ii fatty acid synthase in Plasmodium falciparum are catalyzed by pfacp, pfmcat, and pfKASIII. Biochemistry 42, 1160-1169. doi: $10.1021 / \mathrm{bi0} 26847 \mathrm{k}$ 
Sairam, R. K., Srivastava, G. C., and Saxena, D. C. (2000). Increased antioxidant activity under elevated temperatures: a mechanism of heat stress tolerance in wheat genotypes. Biol. Plant. 43, 245-251.

Salas, J. J., and Ohlrogge, J. B. (2002). Characterization of substrate specificity of plant fata and fatb acyl-acp thioesterases. Arch. Biochem. Biophys. 403, 25-34. doi: 10.1016/s0003-9861(02)00017-6

Sanghera, G. S., and Sharma, V. K. (2011). A critical review on morphophysiological and molecular aspects associated with cold stress in plants. Elixir Agric. 39, 5065-5075.

Stefanov, D., Petkova, V., and Denev, I. D. (2011). Screening for heat tolerance in common bean (Phaseolus vulgaris, 1.) lines and cultivars using jip -test. Sci. Hortic. 128, 1-6. doi: 10.1016/j.scienta.2010.12.003

Strasser, R. J., Tsimillimichael, M., and Srivastava, A. (2004). "Analysis of the chlorophyll a fluorescence transient," in Advances in Photosynthesis \& Respiration, ed. J. Govindjee (Dordrecht: Springer), 321-362.

Sui, N., Li, M., Li, K., Song, J., and Wang, B. S. (2010). Increase in unsaturated fatty acids in membrane lipids of Suaeda salsa, l. enhances protection of photosystem ii under high salinity. Photosynthetica 48, 623-629.

Sun, X., Hu, L., Xie, Y., and Fu, J. (2014). Evaluation of genotypic variation in heat tolerance of tall fescue by functional traits. Euphytica 199, 247-260. doi: 10.1007/s10681-014-1122-4

Takahashi, S., Nakamura, T., Sakamizu, M., Woesik, R. V., and Yamasaki, H. (2004). Repair machinery of symbiotic photosynthesis as the primary target of heat stress for reef-building corals. Plant Cell Physiol. 45, 251-255. doi: 10.1093/pcp/ pch028

Vani, B., Saradhi, P. P., and Mohanty, P. (2001). Alteration in chloroplast structure and thylakoid membrane composition due to heat treatment of rice seedlings: correlation with the functional changes. J. Plant Physiol. 158, 583-592. doi: 10.1078/0176-1617-00260

Veste, M., Bengal, A., Shani, U., Blanke, M., and Pohlan, J. (2000). Impact of thermal stress and high vpd on gas exchange and chlorophyll fluorescence of citrus grandis under desert conditions. Acta Hortic. 531, 143-149.

Vigh, L., Los, D. A., Horváth, I., and Murata, N. (1993). The primary signal in the biological perception of temperature: Pd-catalyzed hydrogenation of membrane lipids stimulated the expression of the desA gene in Synechocystis PCC6803. Proc. Natl. Acad. Sci. U.S.A. 90, 9090-9094. doi: 10.1073/pnas.90.19. 9090

Vigh, L., Maresca, B., and Harwood, J. L. (1998). Does the membrane's physical state control the expression of heat shock and other genes? Trends Biochem. Sci. 23, 369-374. doi: 10.1016/s0968-0004(98)01279-1

Wahid, A., and Close, T. J. (2007). Expression of dehydrins under heat stress and their relationship with water relations of sugarcane leaves. Biol. Plant. 51, 104-109. doi: 10.1007/s10535-007-0021-0

Wakil, S. J., Stoops, J. K., and Joshi, V. C. (1983). Fatty acid synthesis and its regulation. Annu. Rev. Biochem. 52, 537-579. doi: 10.1146/annurev.bi.52. 070183.002541

Wang, F., Ma, J. L., Qin, D. D., Tian, X. J., and Ni, Z. F. (2013). The difference of permeability and membrane lipid composition in heat tolerant and susceptible wheat (Triticum aestivum) under high temperature stress. J. Agric. Biotechnol. 21, 904-910.
Xu, S., Li, J., Zhang, X., Wei, H., and Cui, L. (2006). Effects of heat acclimation pretreatment on changes of membrane lipid peroxidation, antioxidant metabolites, and ultrastructure of chloroplasts in two cool-season turfgrass species under heat stress. Environ. Exp. Bot. 56, 274-285. doi: 10.1016/j. envexpbot.2005.03.002

Yang, S., Wang, F., Guo, F., and Meng, J. J. (2015). Calcium contributes to photoprotection and repair of photosystem II in peanut leaves during heat and high irradiance. J. Integr. Plant Biol. 57, 486-495. doi: 10.1111/jipb. 12249

Yang, W. L., Huang, F. D., Cao, Z. Z., and Lei, B. T. (2013). Effects of high temperature stress on PSII function and its relation to D1 protein in chloroplast thylakoid in rice flag leaves. Acta Agron. Sin. 39, 1060-1068.

Yordanov, I., Velikova, V., and Tsonev, T. (2000). Plant responses to drought, acclimation, and stress tolerance. Photosynthetica 38, 171-186.

Yoshioka, M., Uchida, S., Mori, H., Komayama, K., and Ohira, S. (2006). Quality control of photosystem ?: cleavage of reaction center D1 protein in spinach thylakoids by FtsH protease under moderate heat stress. J. Biol. Chem. 281, 21660-21669. doi: 10.1074/jbc.m602896200

Yusuf, M. A., Kumar, D., Rajwanshi, R., Strasser, R. J., Tsimilli-Michael, M., Govindjee, et al. (2010). Overexpression of $\gamma$-tocopherol methyl transferase gene in transgenic Brassica juncea plants alleviates abiotic stress: physiological and chlorophyll a fluorescence measurements. Biochim. Biophys. Acta 1797, 1428-1438. doi: 10.1016/j.bbabio.2010.02.002

Zabed, H. M., and Shuichi, S. (2013). Physiological Mechanisms of Heat Stress Tolerance in Turfgrass. Saarbrücken: LAP LAMBERT Academic Publishing.

Zhao, B., Jia, W., Gong, H., Wen, X., Ren, H., and Lu, C. (2008). Effects of heat stress on PS II photochemistry in a cyanobacterium Spirulina platensis. Plant Sci. 175, 556-564.

Zhao, Z., Hu, L. X., Hu, T., and Fu, J. M. (2015). Differential metabolic responses of two tall fescue genotypes to heat stress. Acta Pratac. Sin. 2015, 58-69.

Zhong, D., Du, H., Wang, Z., and Huang, B. (2011). Genotypic variation in fatty acid composition and unsaturation levels in bermudagrass associated with leaf dehydration tolerance. J. Am. Soc. Hortic. Sci. 136, 35-40.

Zushi, K., Kajiwara, S., and Matsuzoe, N. (2012). Chlorophyll a, fluorescence ojip transient as a tool to characterize and evaluate response to heat and chilling stress in tomato leaf and fruit. Sci. Hortic. 148, 39-46. doi: 10.1016/j.scienta. 2012.09.022

Conflict of Interest Statement: The authors declare that the research was conducted in the absence of any commercial or financial relationships that could be construed as a potential conflict of interest.

Copyright (c) $2018 \mathrm{Hu}, \mathrm{Bi}, \mathrm{Hu}, \mathrm{Amombo}$, Li and Fu. This is an open-access article distributed under the terms of the Creative Commons Attribution License (CC BY). The use, distribution or reproduction in other forums is permitted, provided the original author(s) and the copyright owner(s) are credited and that the original publication in this journal is cited, in accordance with accepted academic practice. No use, distribution or reproduction is permitted which does not comply with these terms. 